\title{
Pollen dispersal and interspecific gene flow in Louisiana irises
}

\author{
M. L. ARNOLD*, J. J. ROBINSON, C. M. BUCKNER \& B. D. BENNET† \\ Department of Genetics, University of Georgia, Athens, GA 30602, USA
}

\begin{abstract}
An analysis of chloroplast DNA (cpDNA) variation was carried out for 106 individual plants from three natural populations of Louisiana irises. Two of the samples (59 individuals) represented $I$. brevicaulis populations. The third sample was from a population defined by allozyme markers as an area of contact between $I$. fulva, I. hexagona and I. brevicaulis. The cpDNA acts as a seed-specific genetic marker because it is inherited from the maternal parent. cpDNA markers were thus used to discriminate between (i) introgressive hybridization due to seed movement followed by pollen transfer and, (ii) introgression resulting from direct transfer of pollen between allopatric populations of the hybridizing taxa. Furthermore, the concurrent analysis of biparental and maternal markers for the same individuals allowed a test for any directionality in the introgression. A comparison of cpDNA results with data from previous nuclear analyses led to the conclusion that pollen flow occurred from allopatric populations of $I$. hexagona into an area of sympatry involving $I$. fulva and 1 . brevicaulis. In addition, the genotypes detected in the hybrid population indicate that $I$. fulva and $I$. brevicaulis have acted as both pollen and seed parents to produce introgressant individuals. The results of the present study and those of previous nuclear and cpDNA analyses suggest that pollen dispersal is the most important avenue for gene flow between these Iris species.
\end{abstract}

Keywords: chloroplast DNA, introgression, Iris, plants.

\section{Introduction}

One aspect of gene flow in plants, suggested as a major stimulus for evolution, involves the transfer of genetic material between hybridizing taxa (i.e. introgression; Anderson, 1949). The process of introgressive hybridization, like gene flow in general, may act to restrain evolution by leading to the amalgamation of the hybridizing taxa (Grant, 1963). Alternatively, introgression may be evolutionarily creative by facilitating (i) an increase in the fitness of the introgressed form (Nagle \& Mettler, 1969; Bennett, 1989; Bennett \& Grace, 1990), (ii) an invasion of extreme environments by the introgressed form (Lewontin \& Birch, 1966, but see Gibbs, 1968 and Birch \& Vogt, 1970) and/or (iii) the process of speciation (Mecham, 1960; Levin, 1969; Rieseberg et al., 1990). In plants, the first phase of introgressive hybridization may be accomplished by seed dispersal into populations of the alternate taxon followed by pollen transfer (sympatric introgression) or, alternatively, by the transfer of pollen between allo-

\section{*Correspondence.}

†Present address: Espey, Huston \& Associates, Inc., 888 West Belt Dr. South, Suite 200, Houston, TX 77042, USA. patric populations of the hybridizing taxa. The mechanism of interspecific gene flow may have a significant impact on the pattern and extent of dispersal and, thus, the genetic structure of areas of overlap (Barton \& Hewitt, 1985; Asmussen et al., 1989). Furthermore, the avenue of gene flow between hybridizing taxa should either enhance or decrease the likelihood of allopatric introgression (Potts \& Reid, 1988; dePamphilis \& Wyatt, 1989; 1990; Arnold et al., 1990 a, b; 1991).

A classic example of introgressive hybridization involves species from the 'Louisiana Iris' group (Anderson, 1949). Some of the species in this complex have geographical ranges that are closely associated with the Mississippi drainage (I. fulva and I. brevicaulis), while others are associated with freshwater marsh habitats extending from Texas to South Carolina ( $I$. hexagona; Randolph et al., 1967; Bennett, 1989; N. Henderson, personal communication). The habitats associated with each species include moist hardwood forests (I. brevicaulis), understory regions along the banks of bayous derived from the Mississippi river ( $I$. fulva) and open freshwater marshes (I. hexagona; Viosca, 1935; Bennett, 1989). The area of geograph- 
ical overlap between these three species occurs in southern Louisiana and numerous cases of natural hybridization have been reported from this region (Viosca, 1935; Riley, 1938; Anderson, 1949; Randolph et al. 1967; Bennett \& Grace, 1989; Arnold et al., 1990a, b; 1991). Recent studies of this species complex have determined the distribution of nuclear, genetic markers and have led to the inference of both sympatric and allopatric introgression (Arnold et al., 1990a, b; 1991). An initial study of chloroplast DNA (cpDNA) markers for $I$. fulva and I. hexagona suggested that introgression between these two species was a result of pollen being transferred between allopatric populations of the taxa rather than seed dispersal followed by pollen transfer (Arnold et al., 1991). A test for the mechanism of gene flow between these two species was possible because the cpDNA markers are maternally inherited and, therefore, act as seed-specific markers (Arnold et al., 1991). We have extended our analysis of gene flow between iris species by examining cpDNA variation in populations of $I$. brevicaulis and in a population containing nuclear markers characteristic of $I$. brevicaulis, $I$. hexagona and I. fulva. These data were used to test for the presence of maternal lineages originating from these three species. By comparing data for biparentally transmitted nuclear markers (Arnold et al., 1990a, b; 1991) with the maternally transmitted cpDNA markers, we were able to test for introgression resulting from pollen flow between allopatric populations versus introgression due to seed dispersal into populations of the alternate species, followed by pollen transfer. It was also possible to test for any restriction on which species may act as the maternal parent in interspecific crosses.

\section{Materials and methods}

A total of 106 individual iris plants from three populations were examined for chloroplast DNA markers. These populations include two populations identified as $I$. brevicaulis, and one population that had allozyme markers characteristic of $I$. brevicaulis, $I$. fulva and $I$. hexagona (Arnold et al., 1990a). The collection localities for these populations are the following ( $n$ '= sample sizes): I. brevicaulis; Louisiana, St. Martin Parish, St. Martinville, $n=20$; Ascension Parish, Prairieville, $n=39$; Hybrid Population; Louisiana, St. Martin Parish, St Martinville, $n=47$. The hybrid population was estimated to possess hundreds of individual plants and extends semicontinuously for over 1 $\mathrm{km}$. Populations of $I$. brevicaulis are known to occur within $5 \mathrm{~km}$ of this hybrid population. Populations of both $I$. fulva and $I$. hexagona have been sampled within approximately $70 \mathrm{~km}$ of this population. However, there are habitats typically occupied by either $I$. fulva or I. hexagona within a few kilometres of the hybrid population.

DNA isolation was carried out using leaf material and the procedure described by Arnold et al. (1990b). This resulted in the collection of both nuclear and cytoplasmic DNA. The identification of diagnostic cpDNA markers for $I$. brevicaulis, $I$. fulva and $I$. hexagona involved the use of oligonucleotide primers that were designed to anneal to the region containing the ribulose-1, 5-bisphosphate carboxylase gene (i.e. $r b c l$; Z1, 5'-ATGTCACCACAAACAGAAACTAAAGCAAGT-3', McIntosh et al., 1980; ORF106, 5'ACTACAGATCTCATACTACCCC-3', Hiratsuka et al., 1989). The $\mathrm{Z} 1$ primer shares sequence identity with the Zea mays $\mathrm{rbcl}$ gene from positions 1-30 (McIntosh et al., 1980). The ORF106 primer shares sequence identity with the Oryza sativa conserved open reading frame region, ORF106 (Hiratsuka et al., 1989). PCR amplification of this cpDNA region was accomplished using the following protocol: Reaction volume $=100 \mu \mathrm{l}$; reaction $\mathrm{mix}=10 \mathrm{mM}$ Tris- $\mathrm{HCl}(\mathrm{pH}$ 8.3 ), $50 \mathrm{~mm} \mathrm{KCl}, 1.5 \mathrm{~mm} \mathrm{MgCl}_{2}, 0.001 \%$ gelatin, 0.1 mM each of dATP, TTP, dCTP and dGTP, 50 pmol of each primer, $1-2 \mu \mathrm{g}$ of genomic DNA and 2.5 units of Taq DNA polymerase (Perkin Elmer Cetus). The amplification experiments were carried out using a Perkin Elmer Cetus DNA Thermal Cycler. The thermal cycler was programmed for one cycle of $1 \mathrm{~min}$ at $94^{\circ} \mathrm{C}, 35$ cycles of $1 \mathrm{~min}$ at $94^{\circ} \mathrm{C}, 1 \mathrm{~min}$ at either $55^{\circ} \mathrm{C}$ or $60^{\circ} \mathrm{C}, 4 \mathrm{~min}$ at $72^{\circ} \mathrm{C}$ and one cycle of $7 \mathrm{~min}$ at $72^{\circ} \mathrm{C}$. The cpDNA amplification products were used in restriction endonuclease digests to identify diagnostic restriction site or length differences.

Initial digests to identify diagnostic markers for $I$. brevicaulis, I. fulva and I. hexagona involved 10 enzymes (HphI, AluI, BamHI, BstUI, EcoRI, HaeIII, HhaI, HindIII, PstI, and RsaI; New England Biolabs). The various fragments were resolved using $1.5 \%$ agarose gels run at $75 \mathrm{~V}$ for approximately $5 \mathrm{~h}$. EtBr was present in the gels during electrophoresis to allow photography of the restriction fragments under ultraviolet light.

\section{Results}

Figure 1 illustrates both restriction site and length variation between the $r b c l$ amplification products from $I$. brevicaulis, I. fulva and I. hexagona. Amplification of this region of cpDNA from I. fulva and I. hexagona resulted in the production of an approximately $3.2 \mathrm{~kb}$ fragment (Fig. 1; Arnold et al., 1991). In contrast, the amplification product from this region for $I$. brevicaulis individuals was approximately $3.5 \mathrm{~kb}$ in length (Fig. 1; 


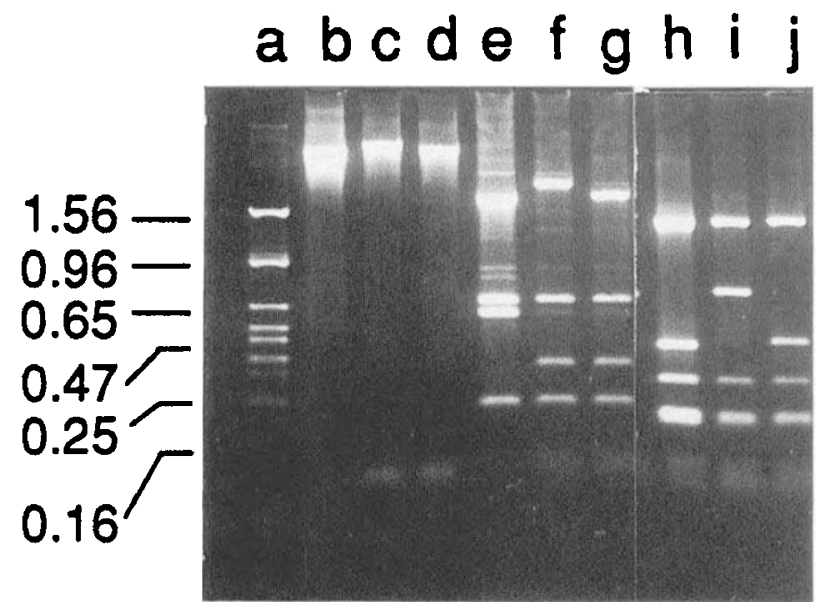

Fig. 1 PCR amplification products and restriction digests of these products from I. fulva, I. brevicaulis and I. hexagona. Lane $\mathrm{a}=\phi \mathrm{X} 174$ DNA digested with $R s a \mathrm{l}$; lane $\mathrm{b}=\mathrm{rbcl}$ region amplification product from $I$. fulva; lane $\mathrm{c}=\mathrm{rbcl}$ region amplification product form $I$. brevicaulis; lane $\mathrm{d}=\mathrm{rbcl}$ region amplification product from $I$. hexagona; lanes $\mathrm{e}-\mathrm{g}$ are the results of $H$ haI restriction digestions of the $r b c l$ amplification products from I. fulva, I. brevicaulis and I. hexagona, respectively; lanes $\mathrm{h}-\mathrm{j}$ are the results of $R s a \mathrm{I}$ restriction digestions of the $r b c l$ amplification products from I. fulva, I. brevicaulis and I. hexagona, respectively.

M. L. Arnold unpublished data). The size difference between I. fulva, I. hexagona and I. brevicaulis is apparent for both the undigested and digested amplification products (Fig. 1). Although the amplification products for I. fulva and I. hexagona are of similar size, these products have a number of restriction site differences (Fig. 1; Arnold et al., 1991). A survey of I. fulva and I. hexagona populations has indicated that these differences are species-specific (Arnold et al., 1991). A difference in the size estimates between the $I$. brevicaulis and the $I$. fulva and I. hexagona digested amplification products is also apparent when the enzyme RsaI is used (Fig. 1). The estimates for the sizes of each of the three species, estimated from the $R s a \mathrm{I}$ experiment, are approximately $0.70 \mathrm{~kb}$ shorter than the estimates from the undigested products. This may be explained by the presence of co-migrating bands and/ or the production of much shorter restriction fragments that were unresolved in our experiments. Arnold et al. (1991) tested the pattern of inheritance of cpDNA in these Iris species by examining artificial $F_{1}$ hybrids produced from crosses of $I$. fulva and $I$. hexagona. These authors detected only the cpDNA markers from the maternal parent in the hybrid offspring.

Three populations were examined using restriction digestion of the $r b c l$ amplification product. Initially we examined individuals using both $H h a I$ and $R s a I$ digests. However, because of the resolution afforded by $a b c d e f g h i j k / m n o p q r s$

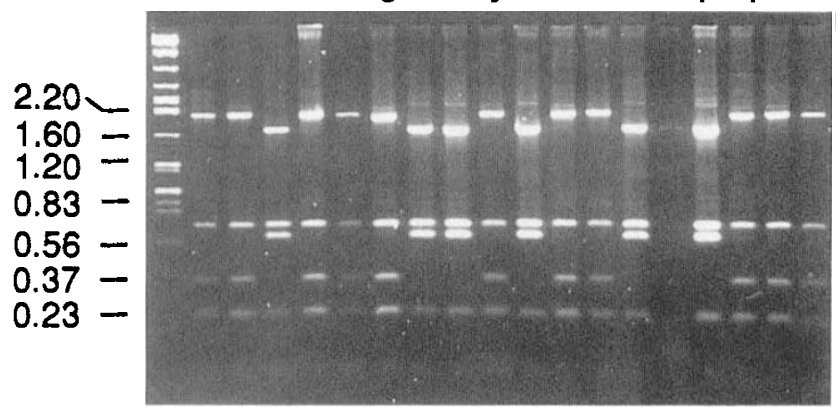

Fig. 2 Hhal restriction digests of PCR amplification products of the $r b c l$ region from individual iris plants in an area of contact between I. fulva, I. brevicaulis and $I$. hexagona. Lane a $=\lambda$ phage DNA digested with BstYI; Lanes b-s contain Hhal digested, amplified DNA from individual iris plants. Individuals in Lanes $b, c, e-g, j, l, m$, q-s have the restriction fragment pattern characteristic of $I$. brevicaulis. The remainder of the individuals possess a restriction fragment pattern diagnostic for I. fulva.

the HhaI digests (Fig. 1) we analysed the majority (97 of the 107 individual plants) of the samples with this enzyme alone. The restriction enzyme analysis of the rbcl amplification products from 59 individuals collected from two $I$. brevicaulis populations failed to resolve any restriction site or length variation. Thus, the restriction fragment length polymorphisms illustrated in Fig. 1 are apparently species-specific for $I$. brevicaulis. In contrast to the two I. brevicaulis populations, the third population sampled included individuals that possessed one of two different haplotypes (Fig. 2). Figure 2 illustrates the HhaI restriction fragment profiles for 18 of the 47 individuals analysed from this population. The two haplotypes resolved were characteristic for either I. brevicaulis or I. fulva (Figs 1 and 2). The remaining 29 individuals also possessed either the I. fulva or I. brevicaulis haplotype. The spatial distribution of the plants sampled from this population and the cpDNA haplotypes are shown in Fig. 3. Fourteen of the individuals surveyed had the $I$. fulva haplotype with the remaining 33 possessing the haplotype characteristic for I. brevicaulis (Fig. 3). Figure 3 also contains data from Arnold et al. (1990a) concerning the nuclear, multilocus genotypes for these 47 individuals. These individuals possess an array of nuclear genotypes that include components from $I$. fulva, I. brevicaulis and I. hexagona (Fig. 3):

\section{Discussion}

The pattern of genetic structuring of plant populations is closely associated with the predominant mechanism of gene flow present in a particular species (Loveless \& 


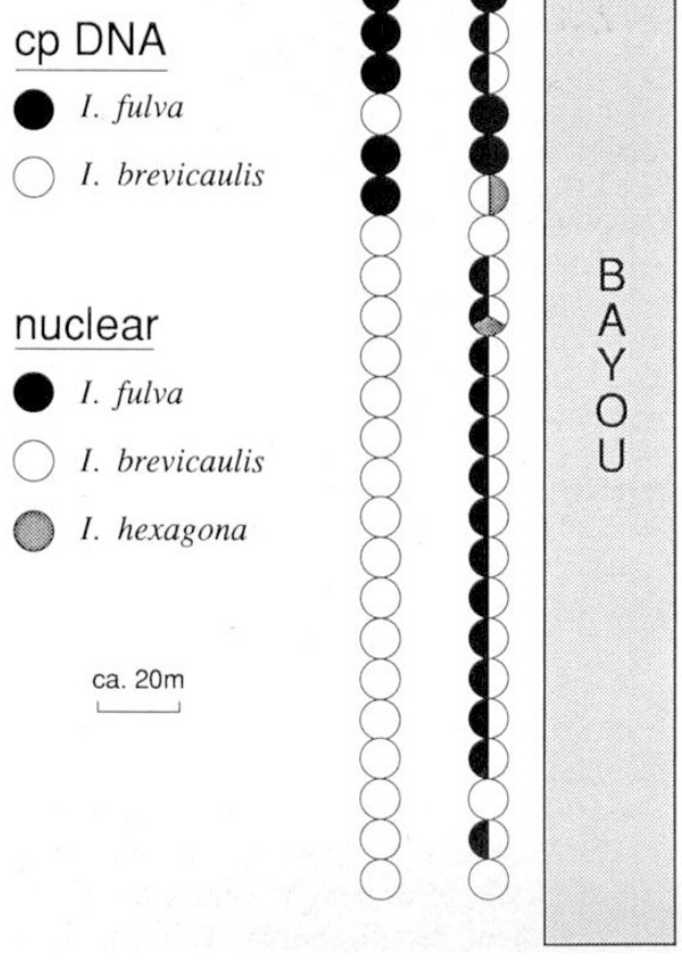



Fig. 3 Chloroplast DNA (cpDNA) and allozyme (nuclear) markers present in each of 47 (no data for one individual) and 48 individual iris plants, respectively. The circles that are arranged beside one another represent cpDNA and nuclear data for the same individual plant. The sample was taken along a linear transect and the individual at the top right-hand corner of this figure is actually located next to the individual at the lower-left hand corner. The allozyme data are from Arnold $e t$ al. (1990a).
Hamrick, 1984). Likewise, the pattern and extent of gene exchange between natural populations of hybridizing taxa will be affected by the likelihood of either pollen or seed immigration into populations of the alternative species. For example, in an experiment involving the introduction of seeds from Phlox drummondii ssp. mcallisteri into a population of $P$. drummondii ssp. drummondii, only limited seed dispersal from the initial point of introduction was detected over an 8-year period (Levin, 1983). Likewise, in a study of natural hybridization between Eucalyptus risdonii and E. amygdalina, estimates of gene flow distances resulting from seed and pollen movement were 4.6 and $82 \mathrm{~m}$, respectively (Potts \& Reid, 1988). The differences in the impact of pollenand seed-mediated gene flow between these two species of Eucalyptus is most likely due to the lack of structures that might facilitate long-distance seed dispersal versus pollination by wide-ranging insects or birds (Potts \& Reid, 1988). A similar conclusion has also been reached for an example of long-distance introgression involving three species of buckeye (Aesculus pavia, A. sylvatica and A. flava). In this study, dePamphilis \& Wyatt (1989) found evidence for an asymmetric transfer of genes between these species up to a distance of $200 \mathrm{~km}$. This pattern of introgression was correlated with the migratory patterns of one of the known pollinators, the ruby-throated hummingbird (dePamphilis \& Wyatt, 1989). These examples emphasize the way in which the pattern and extent of interspecific gene flow may be differentially affected by seed versus pollen dispersal.

Recent genetic analyses of parental and hybrid populations of the Louisiana iris species I. fulva, $I$. hexagona and I. brevicaulis (Arnold et al., 1990a, b; 1991) have supported earlier hypotheses concerning the occurrence of introgressive hybridization (Anderson, 1949). These recent studies have extended the earlier work by detecting apparent introgressive hybridization in both sympatric and allopatric populations of the parental species. In addition, Arnold et al. (1991) carried out an analysis of cpDNA variation in natural populations of $I$. fulva and 1 . hexagona and in an area of overlap between these two species. Findings from this latter analysis suggested that the introgression between these two species was due mainly to pollen movement, and not as a result of seed dispersal followed by pollen transfer (Arnold et al., 1991). This 
conclusion is consistent with data concerning the mode of sexual reproduction in these species. Thus, the major pollinators for this species complex are bees from the subfamily Apinae (Viosca, 1935). Furthermore, hummingbirds have been observed visiting flowers of I. fulva, I. hexagona and natural hybrids (B. D. Bennett, M. L. Arnold, personal observation). These pollinators include species that are capable of long-distance pollination, although the major pollinator species (bumblebees) are known to demonstrate a predominant pattern of near-neighbour foraging in other plant species (Schmitt, 1980; Thomson \& Thomson, 1989). Direct observations concerning seed dispersal in this species complex are lacking. However, inferences can be made concerning the possibility of seed dispersal from the morphology of the fruit and seed and the habitat in which these species normally occur. The seeds produced by all of the iris species in this complex are contained in a large fleshy fruit (Viosca, 1935; Randolph et al., 1967). The release of the seeds from the seed capsule apparently occurs due to the rotting of the capsule. Since the seeds have a corky seed coat that allows them to float (M. L. Arnold, personal observation), and the iris plants are normally located in marshes, swamps or bayous (Viosca, 1935; Randolph et al., 1967; Bennett, 1989), the opportunity for dispersal on water currents would seem to be available.

In the present analysis we have extended our earlier examination of the mechanism of gene flow between $I$. fulva and $I$. hexagona to include a hybrid population involving these two species and $I$. brevicaulis. Such hybrid associations between these three species have been reported previously (Randolph et al., 1967). Furthermore, hybridization between these three species is thought to have resulted in the production of the hybrid species I. nelsonii (Randolph, 1966; Arnold et al., 1990a; 1991). Figure 3 summarizes the cpDNA and allozyme data for each of 47 individuals from such a hybrid population. The data from the nuclear and cpDNA analyses support the hypothesis of localized introgression between I. fulva, I. brevicaulis and $I$. hexagona (Arnold et al., 1990a; present study). These data also indicate that the introgression is bidirectional with respect to $I$. brevicaulis and $I$. fulva. This conclusion can be drawn from the finding of introgressant, nuclear genotypes that have cpDNA haplotypes characteristic of either I. brevicaulis (23 individuals) or I. fulva (seven individuals; Fig. 3). The greater frequency of introgressant types possessing the cpDNA markers characteristic of $I$. brevicaulis suggests that this species has predominated as the seed parent in this population.

The nuclear and cpDNA data from this hybrid population also allow inferences concerning whether the observed introgression has come about in sympatry or has resulted from the transfer of pollen from allopatric populations of the alternative species. In this regard, we have detected seven individuals that have $I$. fulva genotypes and nine individuals that appeared to possess $I$. brevicaulis genotypes (Fig. 3). The detection of apparently pure parental individuals of both I. fulva and $I$. brevicaulis supports the hypothesis that this population is an area of sympatry between these two species. The presence of parental genotypes in a population containing apparent advanced generation backcross individuals (Arnold et al., 1990a; this study) would also indicate a potential for the continued impact of immigrants on the genetic structure of a hybrid population. Levin (1983) has previously demonstrated that immigration by annual plants can indeed have a continued effect on the genetic structure of the recipient population across several generations. In species such as the Louisiana irises, where plants are perennial and have both clonal and sexual modes of reproduction (Bennett, 1989), there should be the opportunity for an extended impact from an immigration episode on the genetic structure and evolution of hybrid populations.

There is incongruence between the cpDNA and nuclear data for this population (Fig. 3) with regard to I. hexagona markers. Thus, we have detected nuclear markers, but not cpDNA markers that are characteristic for this species. This finding is particularly germane with regard to testing for long-distance gene flow due to either pollen or seed dispersal. The lack of I. hexagona seed-specific markers (cpDNA) and the presence of nuclear markers from this species, supports the hypothesis that $I$. hexagona pollen has entered this population from allopatric 1 . hexagona individuals. I. hexagona populations are known to be present within approximately $70 \mathrm{~km}$ of this hybrid population. However, there are habitats within several kilometres of this population that are characteristic of other I. hexagona populations. Therefore, it is possible that there are plants belonging to this species located within $10 \mathrm{~km}$ of the hybrid population.

Nuclear and cpDNA variation in allopatric and sympatric populations of $I$. fulva, $I$. hexagona and $I$. brevicaulis are suggestive of pollen-mediated introgressive hybridization (Arnold et al., 1991; this study). Although rare, long distance seed dispersal, followed by pollen transfer, may occur, the main avenue for the interspecific gene flow appears to be the direct transfer of pollen. Indeed, each of the cases of introgression and hybrid speciation, detected within this species complex (Anderson, 1949; Randolph, 1966; Arnold et al., 1990a, b; 1991; this study), indicate a predominant role for pollen dispersal in the regulation of interspecific gene flow. 


\section{Acknowledgements}

We are grateful to F. Foti for permission to collect Iris samples on his property and to T. Hebert for help with collecting the samples. This research was supported by a NSF grant BSR-9004242 (MLA, JL Hamrick and B. D. B.) and NSF REU supplement (MLA), a Faculty Research Grant from the University of Georgia (MLA) and a grant from the American Iris Society Foundation (BDB and MLA).

\section{References}

ANDERSON, E. 1949. Introgressive Hybridization. John Wiley \& Sons, Inc., New York.

ARNOLD, M. L., HAMRICK, J. L. AND BENNETT, B. D. 1990a. Allozyme variation in Louisiana irises: a test for introgression and hybrid speciation. Heredity, 65, 297-306.

ARNOLD, M. L., BENNETT, B. D. AND ZIMMER, E. A. 1990b. Natural hybridization between Iris fulva and I. hexagona: pattern of ribosomal DNA variation. Evolution, 44, 1512-1521.

ARNOLD, M. L., BUCKNER, C. M. AND RoBinson, J. J. 1991. Pollen mediated introgression and hybrid speciation in Louisiana irises. Proc. Natl. Acad. Sci., U. S. A., 88, 1398-1402.

ASMUSSEN, M. A., ARNOLD, J. AND AVISE, J. C. 1989. The effects of assortative mating and migration on cytonuclear associations in hybrid zones. Genetics, 122, 923-934.

BARTON, N. H. AND HEWITT, G. M. 1985. Analysis of hybrid zones. Ann. Rev. Ecol. Syst., 16, 113-148.

BENNETT, B. D. 1989. Habitat differentiation of Iris fulva Ker Gawler, Iris hexagona Walter, and their hybrids. Ph. D. Thesis, Louisiana State University.

BENNETT, B. D. AND GRACE, J. B. 1990. Shade tolerance and its effect on the segregation of two species of Louisiana Iris and their hybrids. Am. J. Bot., 77, 100-107.

BIRCH, L. C. AND voGT, w. G. 1970. Plasticity of taxonomic characters of the Queensland fruit flies Dacus tryoni and Dacus neohumeralis (Tephritidae). Evolution, 24, 320-343.

GlBBS, G. W. 1968. The frequency of interbreeding between two sibling species of Dacus (Diptera) in wild populations. Evolution, 22, 667-683.

GRANT, v. 1963. The Origin of Adaptations. Columbia University Press, New York.

HIRATSUKA, J., SHIMADA, H., WHITTIER, R., ISHIBASHI, T., SAKAMOTO, M., MORI, M., KONDO, C., HONJl, Y., SUN, C., MENG, B., Ll, Y., KANNO, A., NishiZAWA, Y., HIRAl, A., SHINOZAKI, K., AND SUGIURA, M. 1989. The complete sequence of the rice (Oryza sativa) chloroplast genome: intermolecular recombination between distinct tRNA genes accounts for a major plastid
DNA inversion during the evolution of the cereals. Mol. Gen. Genet., 217, 185-194.

LEVIN, D. A. 1969. The challenge from a related species: a stimulus for saltational speciation. Am. Nat., 103, 316-322.

LEVIN, D. A. 1983. An immigration-hybridization episode in Phlox. Evolution, 37, 575-582.

LEWONTIN, R. C. AND BIRCH, L. C. 1966. Hybridization as a source of variation for adaptation to new environments. Evolution, 20, 315-336.

LOVELESS, M. D. AND HAMRICK, J. L. 1984. Ecological determinants of genetic structure in plant populations. Ann. Rev. Ecol. Syst., 15, 65-95.

McINTOSH, L., POULSEN, C. AND BOGORAD, L. 1980. Chloroplast gene sequence for the large subunit of ribulose bisphosphatecarboxylase of maize. Nature, 288, 556-560.

MECHAM, J. S. 1960. Introgressive hybridization between two southeastern treefrogs. Evolution, 14, 445-457.

NAGLE, J. J. AND METTLER, L. E. 1969. Relative fitness of introgressed and parental populations of Drosophila mojavensis and D. arizonensis. Evolution, 23, 519-524.

de PAMPhILIS, C. W. AND WYATT, R. 1989. Hybridization and introgression in Buckeyes (Aesculus: Hippocastanaceae): a review of the evidence and a hypothesis to explain longdistance gene flow. Syst. Bot., 14, 593-611.

de PAMPHILIS, C. W. AND WYATT, R. 1990. Electrophoretic confirmation of interspecific hybridization in Aesculus (Hippocastanaceae) and the genetic structure of a broad hybrid zone. Evolution, 44, 1295-1317.

POTTS, B. M. AND REID, J. B. 1988. Hybridization as a dispersal mechanism. Evolution, 42, 1245-1255.

RANDOLPH, L. F. 1966. Iris nelsonii, a new species of Louisiana iris of hybrid origin. Baileya, 14, 143-169.

RANDOLPH, L. F., NELSON, 1. S. AND PLAISTED, R. L. 1967. Negative evidence of introgression affecting the stability of Louisiana Iris species. Cornell Univ. Agr. Expt. Stat. Memoir, 398, 1-56.

RIESEBERG, L. H., CARTER, R. AND ZONA, s. 1990. Molecular tests of the hypothesized hybrid origin of two diploid Helianthus species (Asteraceae). Evolution, 44. 1498-1511.

RILEY, H. P. 1938. A character analysis of colonies of Iris fulva, Iris hexagona var. giganticaerulea and natural hybrids. Am. J. Bot., 25, 727-738.

SCHMITT, J. 1980. Pollinator foraging behavior and gene dispersal in Senecio (Compositae). Evolution, 34, 934-943.

THOMSON, J. D. AND THOMSON, B. A. 1989. Dispersal of Erythronium grandiflorum pollen by bumblebees: implications for gene flow and reproductive success. Evolution, 43, 657-661.

vioscA, P., Jr. 1935. The irises of southeastern Louisiana: a taxonomic and ecological interpretation. J. Am, Iris Soc., 57, 3-56. 